\title{
Importance Performance Analysis Pelayanan Jaminan Sosial Kesehatan di Puskesmas Swakelola Pembina
}

\author{
Importance Performance Analysis on Social Health Assurance Service in \\ Puskesmas Swakelola Pembina
}

\author{
Asmaripa Ainy, Misnaniarti, Nur Alam Fajar
}

Program Studi Ilmu Kesehatan Masyarakat Fakultas Kesehatan Masyarakat Universitas Sriwijaya

\begin{abstract}
Abstrak
Kunjungan pasien Jaminan Sosial Kesehatan (Jamsoskes) di puskesmas pembina selama tahun 2009 adalah 24.014 orang. Kunjungan per catur wulan memperlihatkan trend yang menurun. Jumlah pengunjung puskesmas pembina pada periode bulan Januari - April 2009 adalah 9.295 orang, pada Mei - Agustus 2009 adalah 8.162 orang, dan September - Desember 2009 adalah 6.557 orang. Hal ini dapat disebabkan oleh minat masyarakat yang rendah untuk menggunakan Jamsoskes. Oleh sebab itu, perlu dilakukan kajian kualitas pelayanan Jamsoskes menurut perspektif pasien. Penelitian dengan desain cross sectional ini menggunakan data primer yang dilakukan dengan metode wawancara terstruktur atau survei. Sampel terdiri dari 100 pasien Jamsoskes yang mendapat pelayanan di puskesmas pembina dengan metode analisis kesesuaian kinerja (importance-performance analysis/IPA). Berdasarkan hasil penelitian diketahui bahwa rata-rata tingkat kesesuaian antara kinerja dan harapan pasien pada pelayanan Jamsoskes di puskesmas pembina adalah $83,44 \%$. Terdapat dua atribut pada dimensi kualitas pelayanan yang masih perlu ditingkatkan meliputi pemberian perhatian oleh dokter terhadap keluhan-keluhan pasien tentang penyakit serta kenyamanan dan kerapian ruang pengobatan di poli umum. Peran dokter sebagai fasilitator kesembuhan pasien perlu ditingkatkan melalui sikap empati atas berbagai keluhan penyakit pasien serta mempertimbangkan penataan ulang ruangan pelayanan untuk kenyamanan pasien.
\end{abstract}

Kata kunci: Analisis kesesuaian kinerja, jamsoskes, kualitas, puskesmas

\section{Abstract}

The sum of social health assurance (Jamsoskes) patients in puskesmas pembina during 2009 was 24.014 people. There was a decrease in per quarter visits. The sum of patients visit in January to April 2009 was 9.295 people, May to August 2009 was 8.162 people, and September to December 2009 was 6.557 people. This can be caused by the low interest of community to utilize Jamsoskes service. Thus, it should be reviewed about the quality of Jamsoskes service according to the patients' perspective. This research was quantitative survey. The sample was 100 patients of Jamsoskes at puskesmas pembina. Data were collected through interviews using a questionnaire and analyzed by the importance-performance analysis. The average of balance level between service performance and expectation of patients was $83,44 \%$. There were two attributes in the dimensions of service quality that need to be increased: the phycisian attention to the patients complaints about their diseases and convenience and neatness of the treatment room at the general polyclinic. The role of physician as a facilitator of healing to the patient needs to be improved through the attitude of empathy on patient complaints.

Key words: Importance performance analysis, social health assurance, quality, primary health center

\section{Pendahuluan}

Status kesehatan masyarakat yang optimal dapat diwujudkan melalui berbagai upaya antara lain penyelenggaraan pelayanan kesehatan. Kini, kecenderungan peningkatan biaya pemeliharaan kesehatan semakin menyulitkan masyarakat untuk memperoleh pelayanan kesehatan yang layak. Oleh sebab itu, peran pemerintah dalam pendanaan kesehatan menjadi penting. Sistem Jaminan Sosial Nasional (SJSN) yang diatur dalam Undang-Undang Nomor 4 Tahun 2004 bertujuan untuk memberikan jaminan pemenuhan kebutuhan dasar hidup yang layak bagi setiap peserta dan anggota keluarga. ${ }^{1}$ Sejak 22 Januari 2009, pemerintah Provinsi Sumatera Selatan menyelenggarakan program Jaminan

Alamat Korespondensi: Asmaripa Ainy, FKM Universitas Sriwijaya, Jl. Raya Palembang-Prabumulih Km.32 Kampus Univ. Sriwijaya Indralaya Ogan Ilir Sumatera Selatan,Hp.081289365111,e-mail: asny_plbg@yahoo.com 
Sosial Kesehatan Sumatera Selatan Semesta yang disingkat Jamsoskes atau dengan istilah populer program "Berobat Gratis". Program Jamsoskes tersebut memberikan jaminan pada setiap penduduk yang berdomisili di wilayah Provinsi Sumatera Selatan yang belum memiliki jaminan kesehatan. Program Jamsoskes di Kota Palembang diselenggarakan dengan kontribusi dana pemerintah Provinsi Sumatera Selatan dan Pemerintah Kota Palembang secara bersama. ${ }^{2}$ Tujuan program tersebut untuk memperluas cakupan jaminan kesehatan guna memenuhi kebutuhan dasar medis tanpa membedakan status ekonomi penduduk setempat. Kebutuhan dasar medis yang dimaksud adalah kebutuhan pelayanan medis efektif untuk penyembuhan atau mengembalikan produktivitas pasien yang memungkinkan seseorang hidup dan berproduksi.

Selama tahun 2009, pengguna jasa Jamsoskes di 38 puskesmas di Kota Palembang mencapai 408.830 orang meliputi 158.798 laki-laki dan 250.032 perempuan serta 9.089 kasus rujukan. ${ }^{3}$ Pasien tersebut hanya memanfaatkan pelayanan rawat jalan di puskesmas. Total kunjungan pasien Jamsoskes di tahun 2009 terbanyak adalah 58.556 orang di Puskesmas Makrayu dan kunjungan paling sedikit adalah 212 orang di Puskesmas Terapung. Kunjungan pasien Jamsoskes di dua puskesmas tersebut memperlihatkan kecenderungan meningkat pada dua periode pertama pelaporan. Sebaliknya, laporan Dinas Kesehatan Kota Palembang menunjukkan bahwa kunjungan pasien Jamsoskes di puskesmas pembina pada 3 periode pelaporan mengalami penurunan pada Januari April 2009 (9.295), Mei - Agustus 2009 (8.162), dan September - Desember 2009 (6.557). Hal tersebut mengindikasikan minat masyarakat yang rendah terhadap pelayanan Jamsoskes di puskesmas pembina.

Sekretariat Jamsoskes berhasil merangkum keluhan pelanggan Jamsoskes sampai kurun waktu September 2009. Tercatat sejumlah 61 keluhan dari masyarakat dan 42 keluhan mengenai pelayanan kesehatan di Kota Palembang. Keluhan yang utama tentang administrasi kepesertaan dan prosedur pelayanan. Keluhan disampaikan dalam bentuk pertanyaan, konsultasi, dan pengaduan ketidakpuasan baik secara langsung, maupun tidak langsung melalui media telepon, short message service (SMS), surat, dan koran. Penanganan keluhan pelanggan pun telah dilakukan dengan cara menanggapi keluhan dengan memberikan penjelasan tentang berbagai masalah terkait. Hasil observasi awal di puskesmas menemukan informasi dari masyarakat bahwa persyaratan administrasi pelayanan Jamsoskes dipandang rumit. Kualitas pelayanan merupakan unsur penting dalam organisasi jasa karena merupakan salah satu instrumen pengukur kinerja. Kualitas adalah suatu bentuk sikap berhubungan, tetapi tidak sama dengan kepuasan yang merupakan hasil dari perbandingan antara harapan dengan kinerja aktual. ${ }^{4}$ Tingkat kepuasan pelanggan merupakan salah satu tolak ukur kinerja organisasi pelayanan kesehatan yang biasanya diukur dengan menggunakan kriteria pengukuran internal dan eksternal. ${ }^{5}$ Tujuan penelitian ini adalah menganalisis kepuasan pasien terhadap kinerja pelayanan Jamsoskes di puskesmas swakelola pembina dengan menggunakan importance performance analysis.

\section{Metode}

Penelitian dengan desain cross sectional ini menggunakan sumber data primer yang dikumpulkan dengan metode survei melalui wawancara tersruktur. Penelitian dilaksanakan di Puskesmas Swakelola Pembina Palembang Provinsi Sumatera Selatan. Populasi penelitian adalah masyarakat yang memanfaatkan pelayanan Jamsoskes di Puskesmas Swakelola Pembina Palembang. Pengambilan sampel dilakukan dengan metode non probability sampling melalui metode convenience sampling. Responden yang dijadikan sampel adalah pasien yang sebelumnya pernah berkunjung ke Puskesmas Swakelola Pembina Palembang, sedang berada di lokasi penelitian, dan bersedia menjadi responden. Didapatkan ukuran sampel minimal adalah 99,60 yang dibulatkan menjadi 100 orang yang ditarik dari 24.912 pasien Jamsoskes pada tahun 2009.

Sumber data yang digunakan meliputi data primer yang dikumpulkan menggunakan kuesioner yang telah diuji coba terdiri atas 25 item pertanyaan tertutup sesuai dengan 5 dimensi mutu, yaitu reliability, responsiveness, assurance, empathy, dan tangibles. Instrumen tersebut digunakan untuk mendapatkan data tentang persepsi dan harapan masyarakat pengguna Jamsoskes di Puskesmas Swakelola Pembina Palembang. Data sekunder didapatkan melalui telaah dokumen yang terkait dengan program Jamsoskes Sumatera Selatan Semesta. Analisis data dilakukan dengan menggunakan metode original importance performance analysis framework. ${ }^{6}$

Importance performance analysis meliputi analisis kesesuaian antara kinerja pelayanan dan harapan pasien serta analisis kuadran. Data importance performance diproyeksikan pada diagram dua dimensi di mana importance pada sisi $\mathrm{Y}$ dan performance pada posisi X, dilanjutkan dengan pemetaan pada 4 kuadran. Analisis kesesuaian digunakan untuk melihat kesenjangan antara kinerja suatu atribut dengan harapan pelanggan terhadap atribut tersebut. Analisis kuadran dapat digunakan untuk mengetahui respons pelanggan terhadap atribut yang diplotkan berdasarkan tingkat kepentingan dan kinerja atribut tersebut. Analisis kuadran dilakukan dengan membuat diagram yang menggambarkan perpotongan antara nilai rata-rata kinerja dan tingkat harapan sehingga membentuk 4 kuadran meliputi concentrate here, keep up the good work, low priority, dan possible overkill. ${ }^{7}$ 
Tabel 1. Analisis Tingkat Kesesuaian antara Kinerja dan Harapan Dimensi Reliability

\begin{tabular}{|c|c|c|c|c|c|}
\hline Atribut & $\mathbf{K}$ & $\mathbf{H}$ & Rata-rata K & Rata-rata $\mathbf{H}$ & Kesesuaian (\%) \\
\hline Prosedur administrasi penerimaan dilakukan secara cepat & 259 & 323 & 2,59 & 3,23 & 80,19 \\
\hline Dokter memeriksa dan mengobati secara cepat dan tepat & 263 & 333 & 2,63 & 2,33 & 78,98 \\
\hline Perawat melayani secara cepat dan tepat & 262 & 331 & 2,62 & 3,31 & 79,15 \\
\hline Pelayanan dilakukan tepat waktu & 277 & 326 & 2,77 & 3,26 & 84,97 \\
\hline Prosedur tidak berbelit-belit & 273 & 322 & 2,73 & 3,22 & 84,78 \\
\hline
\end{tabular}

Keterangan :

$\mathrm{K}=$ Persepsi Kinerja

$\mathrm{H}=$ Penilaian Harapan

Tabel 2. Analisis Tingkat Kesesuaian antara Kinerja dan Harapan Dimensi Responsiveness

\begin{tabular}{lccccc}
\hline Atribut & K & H & Rata-rata K & Rata-rata H & Kesesuaian (\%) \\
\hline $\begin{array}{l}\text { Dokter tanggap terhadap keluhan pasien } \\
\text { Perawat tanggap terhadap keluhan pasien }\end{array}$ & 287 & 333 & 2,87 & 3,33 & 86,19 \\
$\begin{array}{l}\text { Petugas kesehatan memberikan informasi kesehatan } \\
\text { dengan jelas dan mudah dimengerti }\end{array}$ & 285 & 336 & 2,85 & 3,36 & 84,82 \\
$\begin{array}{l}\text { Petugas administrasi penerimaan pasien tanggap } \\
\text { memberikan pelayanan }\end{array}$ & 256 & 340 & 2,90 & 3,40 & 85,29 \\
$\begin{array}{l}\text { Petugas kesehatan memberi pelayanan rujukan } \\
\text { yang diperlukan secara tanggap }\end{array}$ & 268 & 326 & 2,56 & 3,29 & 77,81 \\
& & & & 3,26 & 82,20 \\
\hline
\end{tabular}

Kuadran I atau concentrate here yang terletak di sebelah kiri atas merupakan wilayah yang memuat berbagai atribut yang dianggap penting oleh pengguna jasa tetapi belum sesuai seperti yang diharapkan. Atribut-atribut kuadran ini harus ditingkatkan dengan melakukan perbaikan secara terus-menerus. Kuadran II atau keep up the good work yang terletak di sebelah kanan atas merupakan wilayah yang memuat berbagai atribut yang dianggap penting oleh pengguna jasa dan sudah sesuai dengan yang mereka rasakan, sehingga tingkat kepuasan relatif lebih tinggi. Atribut-atribut ini harus tetap dipertahankan karena menjadikan jasa tersebut unggul bagi pelanggan. Kuadran III atau low priority yang terletak di sebelah kiri bawah merupakan wilayah yang dianggap kurang penting oleh pengguna jasa dan kinerja tidak terlalu istimewa. Peningkatan kelompok atribut ini tetap dapat dipertimbangkan karena pengaruh manfaat yang dirasakan pengguna jasa. Kuadran IV atau possible overkill yang terletak di sebelah kanan bawah merupakan wilayah yang dianggap kurang penting oleh pengguna jasa dan dirasakan terlalu berlebih-lebihan sehingga atribut-atribut ini dapat dikurangi.

\section{Hasil}

Puskesmas pembina dikenal dengan puskesmas perawatan ibu bersalin 24 jam yang meliputi wilayah kerja Kelurahan Silaberanti dan Kelurahan Seberang Ulu I dengan jumlah penduduk 26.611 jiwa. Untuk memenuhi kebutuhan masyarakat, puskesmas pembina mempunyai berbagai program pokok meliputi promosi kesehatan, sanitasi, kesehatan ibu dan anak/keluarga berencana (KIA/KB), gizi, pencegahan dan pemberantasan penyakit (P2P), serta 3 program spesifik meliputi klinik kesehatan reproduksi, klinik gizi, imunisasi, dan lingkungan masyarakat (gilingan mas), dan klinik gawat darurat. Petugas pada unit Jamsoskes terdiri dari penanggung jawab, komputerisasi, dan registrasi pasien. Kunjungan pasien Jamsoskes pada periode bulan Januari hingga Juni 2010 adalah 13.209 pasien, tertinggi pada bulan Januari (2.253 pasien) dan terendah pada bulan Mei (1.974 pasien). Jika diakumulasikan per tiga bulan, kunjungan pasien terlihat menurun dari 7.086 pasien menjadi 6.223 pasien. Rata-rata umur responden adalah 32 tahun dengan rentang umur antara 16 tahun sampai 75 tahun. Mayoritas responden berumur 21 tahun (34\%). Berdasarkan hasil penelitian diketahui bahwa sebagian besar responden adalah perempuan $(91 \%)$ dan berpendidikan tamat SMA/sederajat (53\%).

\section{Analisis Kesesuaian Pelayanan Jamsoskes}

Tingkat kesesuaian adalah hasil perbandingan antara skor kinerja dengan skor harapan pasien dari 5 dimensi yang memengaruhi kepuasan pasien terhadap kualitas pelayanan Jamsoskes di Puskesmas Pembina Palembang. Harapan dan persepsi dapat membentuk kepuasan karena kepuasan adalah kesesuaian antara persepsi jasa yang diterima dengan harapan yang diinginkan. Tingkat kesesuaian kinerja dan harapan pasien terhadap pelayanan Jamsoskes yang diterima selama berobat di Puskesmas Pembina Palembang. Pada penelitian ini, nilai 
Tabel 3. Analisis Tingkat Kesesuaian antara Kinerja dan Harapan Dimensi Assurance

\begin{tabular}{lccccc}
\hline Atribut & K & H & Rata-rata K & Rata-rata H & Kesesuaian (\%) \\
\hline Kemampuan dokter menjelaskan penyakit yang diderita & 277 & 324 & 2,77 & 3,24 & 85,49 \\
Pengetahuan dan kemampuan dokter mendiagnosis penyakit & 287 & 320 & 2,87 & 3,20 & 89,69 \\
Jaminan keamanan dan kepercayaan pada pelayanan yang diberikan & 283 & 335 & 2,83 & 3,35 & 84,48 \\
Dokter memberikan pelayanan secara sopan dan ramah & 280 & 331 & 2,80 & 3,31 & 84,59 \\
Perawat memberikan pelayanan secara sopan dan ramah & 274 & 328 & 2,74 & 3,28 & 83,53 \\
\hline
\end{tabular}

Tabel 4. Analisis Tingkat Kesesuaian antara Kinerja dan Harapan Dimensi Empathy

\begin{tabular}{llrrrr}
\hline Atribut & K & H & Rata-rata K & Rata-rata H & Kesesuaian (\%) \\
\hline Perhatian dokter terhadap keluhan pasien terhadap penyakitnya & 269 & 337 & 2,69 & 3,37 \\
Pelayanan yang adil tanpa memandang status sosial & 281 & 332 & 2,81 & 3,32 & 89,82 \\
Kesungguhan dokter dan perawat mengatasi penyakit pasien & 278 & 330 & 2,78 & 3,30 & 84,24 \\
Kesungguhan petugas adminisrasi mengurus rujukan ke rumah sakit & 276 & 329 & 2,76 & 3,29 & 83,89 \\
Komunikasi antara petugas kesehatan dengan pasien & 280 & 327 & 2,80 & 3,27 & 85,62 \\
yang baik dan lancar & & & & & \\
\hline
\end{tabular}

Tabel 5. Analisis Tingkat Kesesuaian antara Kinerja dan Harapan Dimensi Tangible

\begin{tabular}{|c|c|c|c|c|c|}
\hline Atribut & $\mathbf{K}$ & $\mathbf{H}$ & Rata-rata K & Rata-rata $\mathbf{H}$ & Kesesuaian (\%) \\
\hline Kebersihan ruang tunggu puskesmas & 287 & 336 & 2,87 & 3,36 & 85,41 \\
\hline Kenyamanan dan kerapian ruang pengobatan di poli umum & 275 & 342 & 2,75 & 3,42 & 80,40 \\
\hline Kebersihan dan kerapian penampilan petugas kesehatan & 290 & 330 & 2,90 & 3,30 & 87,88 \\
\hline Kelengkapan, kesiapan, dan kebersihan alat kesehatan & 276 & 341 & 2,76 & 3,41 & 80,94 \\
\hline
\end{tabular}

rata-rata seluruh dimensi yang memengaruhi kepuasan pasien Jamsoskes di puskesmas pembina adalah 83,44\%. Pada setiap dimensi masih terdapat nilai kesesuaian di bawah nilai rata-rata. Pada dimensi reliability, terdapat 3 atribut yang memiliki persentase kesesuaian di bawah rata-rata $(83,44 \%)$. Pertama, prosedur administrasi penerimaan dilakukan secara cepat; kedua, dokter memeriksa dan mengobati secara cepat dan tepat; ketiga, perawat melayani secara cepat dan tepat (Tabel 1).

Terdapat dua atribut pada dimensi responsiveness dengan persentase kesesuaian di bawah rata-rata. Pertama, petugas administrasi penerimaan pasien tanggap dalam memberikan pelayanan. Kedua, petugas kesehatan memberi pelayanan rujukan yang tanggap jika diperlukan (Tabel 2). Pada dimensi assurance, semua atribut memiliki persentase kesesuaian lebih dari ratarata total dimensi kualitas (Tabel 3).

Pada dimensi empathy ada satu atribut dengan persentase kesesuaian di bawah rata-rata, yakni dokter memberikan perhatian terhadap keluhan-keluhan yang diutarakan pasien terhadap penyakitnya (Tabel 4).

Pada dimensi tangibles ada 3 atribut dengan persentase kesesuaian di bawah nilai rata-rata total. Pertama, kenyamanan ruang tunggu di puskesmas; kedua, kenya- manan dan kerapian ruang pengobatan di poli umum; ketiga, kelengkapan, kesiapan, dan kebersihan alat-alat kesehatan yang digunakan (Tabel 5).

\section{Pembahasan}

Pelayanan Jamsoskes merupakan implementasi kebijakan dari pemerintah Provinsi Sumatera Selatan untuk meningkatkan cakupan masyarakat dalam mendapatkan jaminan kesehatan. Puskesmas pembina yang merupakan salah satu puskesmas di wilayah Kota Palembang Provinsi Sumatera Selatan turut menyelenggarakan pelayanan Jamsoskes bagi penduduk di wilayah setempat. Hal ini sejalan dengan upaya pencapaian Universal Health Coverage di tahun 2014 yang telah menjadi isu penting dalam pembiayaan kesehatan di Indonesia saat ini menuju peningkatkan derajat kesehatan masyarakat. Hal ini sejalan dengan penelitian yang menyebutkan bahwa perluasan akses pelayanan kesehatan memegang peranan penting dalam meningkatkan derajat kesehatan masyarakat. 8

Pelayanan Jamsoskes yang diberikan oleh petugas kesehatan di puskesmas pembina masih belum mampu memenuhi harapan serta keinginan pasien yang berobat. Hal ini dapat terlihat dari 9 atribut yang masih memiliki 


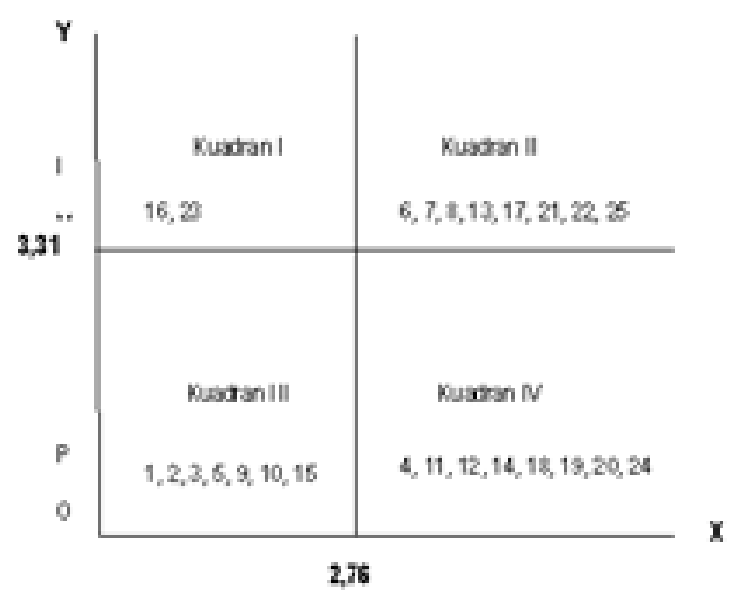

Gambar 1. Diagram Kartesius Pelayanan Jamsoskes di Puskesmas Pembina

nilai di bawah nilai rata-rata seluruh dimensi sehingga menjadi penting bagi pihak puskesmas pembina untuk terus meningkatkan kualitas pelayanan karena kualitas pelayanan tidak dapat dinilai hanya berdasarkan sudut pandang puskesmas tetapi juga sudut pandang pasien sebagai pelanggan. Pihak yang sangat menentukan mutu pelayanan adalah pelanggan. Fokus pada kebutuhan dan harapan pelanggan diperkenalkan sebagai kunci peningkatan mutu oleh Deming, Juran, Crosby, dan pencetus Total Quality Management (TQM) lainnya. ${ }^{9}$

Harapan dan persepsi dapat membentuk kepuasan karena kepuasan adalah kesesuaian antara persepsi jasa yang diterima dengan harapan yang diinginkan. Tingkat kesesuaian kinerja dan harapan pasien terhadap pelayanan Jamsoskes yang diterima selama berobat di Puskesmas Pembina Palembang. ${ }^{10}$ Pada penelitian ini, tingkat kepuasan pasien digambarkan sesuai dengan 5 dimensi kualitas pelayanan jasa yang meliputi reliability, responsiveness, assurance, empathy, dan tangible. ${ }^{11}$ Reliability atau keandalan adalah kemampuan memberikan pelayanan yang dijanjikan dengan segera/tepat waktu, akurat, dan memuaskan. Responsiveness atau daya tanggap adalah kemauan/kesediaan para karyawan maupun tenaga medis untuk membantu masyarakat dan memberikan pelayanan dengan tanggap. Assurance atau jaminan mencakup pengetahuan, kompetensi, kesopanan, respect terhadap pelanggan, dan sifat dapat dipercaya dari para petugas kesehatan. Empathy merupakan kemudahan dalam melakukan hubungan, komunikasi yang baik, perhatian pribadi dan memahami kebutuhan masyarakat. Tangibles atau bukti langsung meliputi fasilitas fisik serta perlengkapan dan sarana fisik lainnya. Lupiyoadi, ${ }^{12}$ juga menyatakan bahwa tangibles adalah kemampuan suatu organisasi dalam menunjukkan eksistensi kepada pihak eksternal. Dimensi tangibles penting diperlukan sebagai ukuran terhadap pelayanan jasa di mana pasien dapat merasakan melalui indra penglihatan untuk menilai suatu kualitas pelayanan. Oleh karena sifat jasa yang tidak berwujud maka pasien akan sangat memperhatikan benda berwujud pada institusi yang memberikan pelayanan sebagai patokan terhadap kualitas jasa.

Konsep pengukuran tingkat kepuasan pelanggan berasal dari konsep service quality. Tingkat kepentingan pelanggan (customer expectation) diukur dalam kaitannya dengan apa yang seharusnya dikerjakan oleh tempat pelayanan agar menghasilkan jasa yang berkualitas tinggi. ${ }^{5}$

Berdasarkan diagram dapat ditemukan bahwa atribut dokter memberikan perhatian terhadap berbagai keluhan penyakit yang diutarakan pasien serta kenyamanan dan kerapian ruang pengobatan di poli umum sangat penting ditingkatkan kinerjanya karena kedua atribut ini dipersepsikan sangat penting, ditunjukkan dengan tingkat importance tinggi. Akan tetapi pada kenyataannya pasien pengguna jasa Jamsoskes menilai kedua hal tersebut belum memenuhi harapan. Menurut Barsky, ${ }^{13}$ peringkat importance yang rendah cenderung memainkan peran yang lebih rendah dalam memengaruhi persepsi pelanggan secara keseluruhan, sedangkan peringkat importance yang tinggi cenderung lebih penting dalam menentukan kepuasan pelanggan.

Kualitas pelayanan kesehatan dikaitkan dengan kehendak memenuhi kebutuhan para pemakai jasa pelayanan kesehatan. Semakin sempurna pemenuhan kebutuhan tersebut semakin baik pula kualitas pelayanan. ${ }^{14}$ Berdasarkan posisi atribut dalam diagram, pendorong utama kepuasan pelanggan mungkin untuk mengidentifikasi, sehingga strategi pemasaran yang sesuai dapat dikembangkan. Dengan kata lain, alokasi terbaik sumber daya dapat ditentukan berdasarkan hasil identifikasi menggunakan analisis importance performance untuk memaksimalkan kepuasan pelanggan.

\section{Kesimpulan}

Hasil importance performance analysis pelayanan Jamsoskes di puskesmas pembina menunjukkan bahwa rata-rata tingkat kesesuaian antara kinerja dan harapan pasien pada pelayanan Jamsoskes di puskesmas pembina sebesar $83,44 \%$. Berdasarkan analisis kuadran menggunakan diagram kartesius, terdapat dua atribut pada dimensi kualitas pelayanan yang perlu ditingkatkan yakni dokter memberikan perhatian terhadap keluhan-keluhan yang diutarakan pasien terhadap penyakitnya serta kenyamanan dan kerapian ruang pengobatan di poli umum. Peningkatan kualitas pelayanan Jamsoskes yang berkesinambungan menjadi salah satu kunci penting yang mengisyaratkan bahwa pelayanan harus dilakukan sesuai standar dan memenuhi kaidah-kaidah kualitas yang 
berorientasi kepada kepentingan pelanggan, yang artinya puskesmas sebagai penyedia pelayanan harus terus beradaptasi dengan kebutuhan pelanggan.

\section{Saran}

Peran dokter sebagai fasilitator kesembuhan pasien perlu ditingkatkan melalui sikap empati atas berbagai keluhan penyakit pasien. Pihak puskesmas juga perlu mempertimbangkan penataan ulang ruangan pelayanan untuk kenyamanan pasien dan selanjutnya secara kontinu diidentifikasi faktor-faktor determinan kepuasan pasien agar strategi peningkatan kualitas pelayanan Jamsoskes dapat dikembangkan secara komprehensif.

\section{Ucapan Terima Kasih}

Terima kasih diucapkan kepada Lembaga Penelitian Universitas Sriwijaya yang mendanai penelitian ini melalui Daftar Isian Pelaksanaan Anggaran (DIPA) Universitas Sriwijaya tahun anggaran 2010.

\section{Daftar Pustaka}

1. Sekretaris Negara Republik Indonesia. Undang-undang nomor 40 tahun 2004 tentang sistem jaminan sosial nasional. Jakarta: Sekretaris Negara Republik Indonesia; 2004.

2. Dinas Kesehatan Provinsi Sumatera Selatan. Pedoman pelaksanaan program jaminan sosial kesehatan Sumatera Selatan semesta tahun 2009. Palembang: Dinas Kesehatan Provinsi Sumatera Selatan; 2009.

3. Dinas Kesehatan Kota Palembang. Profil dinas kesehatan Kota Palembang. Palembang: Dinas Kesehatan Kota Palembang; 2009.
4. Suprapto J. Pengukuran tingkat kepuasan pelanggan untuk menaikkan pangsa pasar. Jakarta: PT Rineka Cipta; 2006.

5. Rangkuti F. Measuring customer satisfaction: teknik mengukur dan strategi meningkatkan kepuasan pelanggan plus analisis kasus PLN-JP. Jakarta: PT Gramedia Pustaka Utama; 2008.

6. Bacon DR. A comparison of approaches to importance performance analysis. International Journal of Market Research. 2003; 45 (1): 55-71.

7. Brandt DR. An outside in approach to determining customer-driven priorities for improvement and innovation. White Paper Series. 2000 [cited 2010 November 1]. Available from: http://www.burke.com/ whitepapers/Burke\%20Overview\%20v1\%20pdf.pdf.

8. Mukti AG. Mencari alternatif model sistem pembiayaan kesehatan berbasis asuransi kesehatan sosial di era desentralisasi. Jurnal Manajemen Pelayanan Kesehatan. 2003.

9. Jablonski R. Customer focus: the cornerstone of quality management. 1992 [cited 2010 October 15]. Available from: http://www.findarticles.com/p/articles/mi-m3257/isn11-v46.

10. Nurjanah MAG. Tingkat kepuasan peserta gadjah mada medical center (GMC) terhadap mutu pelayanan kesehatan [tesis]. Yogyakarta: Fakultas Kedokteran Universitas Gadjah Mada; 2002.

11. Tjiptono F. Prinsip-prinsip total quality service. Yogyakarta: Penerbit Andi; 2003.

12. Lupiyoadi R. Manajemen pemasaran jasa. Jakarta: Salemba Empat; 2001.

13. Barsky JD. World-class customer satisfaction. Chicago: Irwin Publishing; 1995.

14. Kurniasari A, Kuntjoro T. Analisis kebutuhan pelanggan puskesmas pijoan baru Provinsi Jambi [tesis]. Yogyakarta: Fakultas Kedokteran Universitas Gadjah Mada; 2006. 